
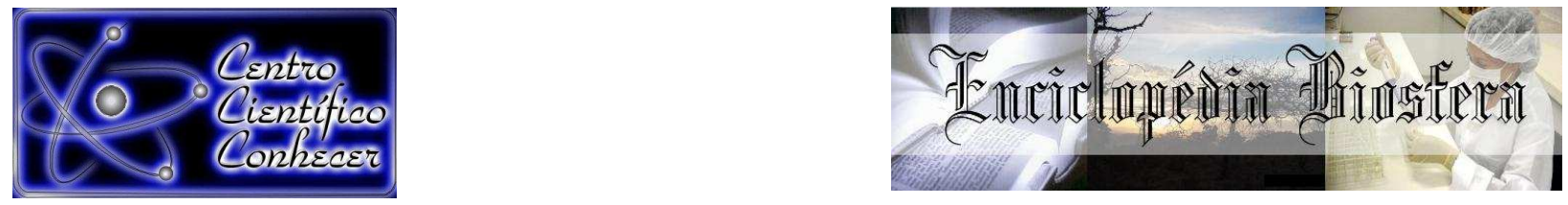

\title{
BIOMARCADORES NO DIAGNÓSTICO PRECOCE DA INJÚRIA RENAL AGUDA
}

\author{
Luma Tatiana Silva Castro ${ }^{1}$, Mariana Dall'Agnol ${ }^{2}$, Manoella Sena Araujoº ${ }^{2}$, Maria \\ Clorinda Soares Fioravanti ${ }^{3}$, Paula Costa Ariza ${ }^{4}$,
}

1 Doutoranda em Ciência Animal, Escola de Veterinária e Zootecnia (EVZ), Universidade Federal de Goiás (UFG) luma.medvet@gmail.com

2 Estudante de Graduação em Medicina Veterinária, EVZ/UFG

3 Professora Doutora do departamento de Medicina Veterinária, EVZ/UFG

4 Doutoranda em Ciência Animal, Escola de Veterinária e Zootecnia (EVZ),

Universidade Federal de Goiás (UFG)

Recebido em: 08/04/2016 - Aprovado em: 30/05/2016 - Publicado em: 20/06/2016 DOI: 10.18677/Enciclopedia Biosfera 2016 021

\begin{abstract}
RESUMO
A injúria renal aguda (IRA) consiste no decréscimo da função renal, com rápida evolução do quadro. O diagnóstico precoce é fundamental para o estabelecimento do tratamento adequado, objetivando reestabelecer a função renal antes que a lesão se perpetue ou leve a morte do animal. A creatinina sérica tem sido utilizada para o estabelecimento da função renal, entretanto este marcador mostra-se ineficiente para a detecção precoce do dano renal agudo. A alta demanda por testes e marcadores capazes de detectar estágios iniciais da injúria renal vem impulsionando o estudo de novas ferramentas diagnósticas. Na medicina, a aplicação experimental de diversos biomarcadores já é realidade, no entanto na medicina veterinária o alto custo dos ensaios, a carência de reagentes espécie específicos representam grandes entraves. Alguns marcadores como N-acetil-beta-d-glicosaminidase (NAG), Y- glutamil-transpeptidase (GGT), Fosfatase alcalina (ALP) e Cistatina C já vem sendo estudados na medicina veterinária. Destes, a cistatina $C$ ocupa posição de destaque, devido ao fato de que a técnica já foi validada na experimentação em animais e é menos custosa. Serão apresentados, neste trabalho, novas ferramentas diagnosticas de IRA, apontando biomarcadores em estudo na medicina e na medicina veterinária.
\end{abstract}

PALAVRAS-CHAVE: avaliação da função renal, ferramentas diagnósticas, insulto renal agudo.

\section{ACUTE KIDNEY INJURY BIOMARKERS}

\begin{abstract}
Acute kidney injury $(\mathrm{AKI})$ is an insult which reduces renal function. This disease process needs to be recognize as soon as possible since it requires immediate and aggressive intervention to completely remission and to avoid animal death. Serum creatinine has been used for a long time as a renal function marker however its not
\end{abstract}


adequate detecting $\mathrm{AKI}$. New biomarkers that are capable of detect $\mathrm{AKI}$ has been testing in medicine and veterinary medicine to find new biomarkers adequate to detect AKI. Some biomarkes such as N-acetyl- $\beta$-D-glucosaminidase (NAG), Gammaglutamyl transferase (GGT), Alkaline phosphatase (ALP) and cystatin $C$ has been tested in veterinary medicine. Among these biomarkers mentioned, cystatin $\mathrm{C}$ plays a importante role in veterinary medicine since had positive results in clinical trials and it is less costly. This review article will be presenting new biomarkers to detect AKI in veterinary medicine since possessing this early detection will allow a more accurate prognosis and afford the best chance of a favorable outcome to pets.

KEYWORDS: acute renal insult, new diagnostic markers, renal function evaluation.

\section{INTRODUÇÃO}

A injúria renal aguda (IRA) consiste no decréscimo da função renal, com rápida evolução, podendo progredir em poucas horas ou em alguns dias, culminando no acúmulo de metabólitos nitrogenados na circulação, que resulta em azotemia (SIROTA et al., 2011). O maior desafio para a maioria dos clínicos, em relação a esta síndrome, é a detecção nos estágios iniciais. Apesar dos estudos recentes para o estabelecimento da patogenia e estabelecimento de novas estratégias terapêuticas, a mortalidade envolvendo a IRA ainda continua elevada. (MEDIĆ et al., 2016). Nesse sentido, o diagnóstico laboratorial precoce é fundamental para o estabelecimento do tratamento adequado, capaz de reestabelecer a função renal antes que a lesão se perpetue (BELCHER et al., 2011; BELLOMO et al., 2012).

Há 95 anos, o diagnóstico da injúria renal, é confirmado laboratorialmente pela quantificação sérica de creatinina. Apesar de amplamente utilizada na rotina clínica, esse marcador tem limitações na detecção precoce do dano renal (BELCHER et al., 2011; BELLOMO et al., 2012; VIJAYAN et al., 2016), uma vez que o aumento é detectável somente quando $75 \%$ dos néfrons encontram-se afuncionais (WARE, 2015; HSU, et al., 2014), carecendo em sensibilidade e especificidade para a IRA (SIEW et al., 2011). Além disso, a concentração sérica de creatinina é influenciada pelo peso corpóreo, idade, sexo, raça, massa muscular e ingestão proteica. Portanto, trata-se de um marcador pouco sensível na detecção precoce da IRA (BRAUN et al., 2003).

A demanda por um teste capaz de detectar os estágios iniciais da injúria renal fez surgir novas ferramentas diagnósticas. A medicina tem estudado amplamente o tema e vem desenvolvendo marcadores precoces da IRA. Na última década, a Sociedade Americana de Nefrologia estabeleceu o estudo de novos biomarcadores como a prioridade dentre as pesquisas a serem desenvolvidas (KOVALINKA, 2014). Entende-se por biomarcadores medidas experimentais que indicam a ocorrência de uma determinada função normal ou patológica de um organismo ou uma resposta a um agente farmacológico.

Com a presente revisão serão descritas novas ferramentas diagnósticas de IRA na medicina e na medicina veterinária, considerando a função, caracterização e possibilidade de aplicação na rotina clínica de biomarcadores renais em potencial. 


\section{DESENVOLVIMENTO}

\section{Caracterização da injúria renal aguda \\ Nomenclatura}

Injúria renal aguda (IRA) é o novo termo consensual para substituir a antiga nomenclatura "Insuficiência renal aguda". Esta modificação ocorreu, pois o termo "insuficiente" transmite uma ideia errônea de que esse rim já não é capaz de exercer suas funções que, no caso da IRA, encontram-se reduzidas entrementes, não totalmente afuncionais (BELLOMO et al., 2012; MONAGHAN et al., 2012).

\section{Conceito}

O conceito estabelecido de IRA compreende a redução abrupta da função renal que culmina em alterações na taxa de filtração glomerular (TFG), débito urinário, produção de urina e função tubular (KELLUM et al., 2011). Como consequência dessas alterações, ocorre o acúmulo de compostos nitrogenados, como a ureia e a creatinina, resultando em azotemia (RUFATTO et al., 2011). Adicionalmente, estão presentes alterações no balanço hídrico, eletrolítico e ácidobase (BIRCHARD \& SHERDING, 2008).

\section{Epidemiologia}

Na medicina, a IRA é diagnosticada anualmente, em 5.000 pessoas a cada um milhão sendo uma condição que afeta, pelo menos, $40 \%$ dos pacientes críticos que apresentam sepse (BELLOMO et al., 2012). A mortalidade varia entre $45 \%$ a $64 \%$ nos pacientes humanos (COBRIN et al., 2013).

$\mathrm{Na}$ medicina veterinária, tanto cães quanto gatos são consideravelmente acometidos pela IRA, e esta ocorrência ainda não está totalmente esclarecida (MONAGHAN et al., 2012). Além disso, todas as faixas etárias têm chances iguais de desenvolver a síndrome clínica (RUFATTO et al, 2011). Diferentemente da resolução em humanos, os pacientes caninos e felinos afetados apresentam alta mortalidade girando em torno de $50 \%$ a $60 \%$ (COBRIN et al., 2013).

Nos cães em situação crítica, o índice de mortalidade é de $54,2 \%$ (THOEN \& KERL, 2011). Em um estudo retrospectivo feito pela North Carolina State University com 99 cães, 56\% foram submetidos à eutanásia, 19\% tiveram remissão completa e $25 \%$ tornaram-se DRC (VADEN et al., 1997).

Em outro estudo para a caracterização do paciente com IRA e seu prognóstico, realizado pela universidade dos Estados Unidos, a Garden State Veterinary Specialists, constatou que em uma amostragem de 32 animais, 53\% sobreviveram, destes, $25 \%$ tiveram remissão completa e $28 \%$ cronificaram (WORWAG \& LANGSTON, 2008). Em uma avaliação retrospectiva realizada na Escola de Veterinária da Universidade da Califórnia (Davis) aferindo a evolução da IRA, $28 \%$ dos gatos morreram, $30 \%$ foram submetidos à eutanasia e $42 \%$ tiveram que ser submetidos a 30 dias de hemodiálise até receberem alta (SEGEV et al., 2013).

\section{Etiologia da injúria renal aguda}

A etiologia da IRA varia de acordo com a espécie. Em gatos, a causa inicial da IRA ainda é indeterminada, no entanto, as toxinas parecem estar relacionadas em $50 \%$ dos pacientes (WORWAG \& LANGSTON, 2008). Já foram descritas como causas: ingestão de medicamentos nefrotóxicos, como anti- 
inflamatórios não esteroidais (AINES), aminoglicosídeos, doxorubicina, vitamina D ou ingestão acidental de raticidas; contaminantes alimentares como o ácido úrico; intoxicação por lírio; injúria isquêmica; infecção do trato urinário superior (pielonefrite); neoplasia, obstrução ureteral ou uretral e sepse (MONAGHAN et al., 2012; HSU et al., 2014).

Em cães, os agentes tóxicos também são importantes. A anfotericina B, aminoglicosídeo, quimioterápicos e AINES são fármacos indutores de IRA. Outras causas são agentes infecciosos indutores de pielonefrite aguda, como a Leptospira $s p$. e microrganismos do tipo riquétsias que desencadeiam o dano ou por meio da ativação da cascata da inflamação ou por vasculite (XAVIER et al., 2008). As neoplasias renais, hipercalcemia, traumatismo e doenças imunomediadas também estão relacionadas à síndrome (WINGFIELD, 2004).

Como causas iatrogênicas estão vasodilatadores (GREENE \& GRAUER, 2013), a anestesia prolongada ou não, que apresenta como fator desencadeante a hipotensão e a hipovolemia que podem produzir vasoconstrição renal, isquemia renal e IRA (SLADEN, 1993; HARA et al., 1998). Anestésicos liberadores de catecolaminas como cetamina, tiletamina e óxido nitroso podem aumentar ou diminuir o fluxo sanguíneo renal (FSR) (HARA et al., 1998). O FSR e a TFG podem ser afetados pelos anestésicos inalatórios de maneira dose-dependente como por exemplo, o halogenado isofluorano que tem pouco efeito sobre FSR porém, pode diminuir a TFG e débito urinário (HARA et al., 1998).

A anestesia como etiologia da IRA é afetada pelo grau de hidratação e fluidos administrados durante o transoperatório. Injúrias renais pré-existentes podem agravar as consequências deletérias dos anestésicos na função renal (GREENE \& GRAUER, 2013).

Em pacientes com função renal normal, o sevofluorano foi capaz de induzir hipotensão, acompanhada de alterações tubulares renais, detectáveis duas horas após o término do procedimento (LUBRANO et al., 2008). Disfunção tubular transitória decorrente de hipotensão por propofol e remifentanila em pacientes sem doença renal, também foram relatadas e minimizadas com administração de $\alpha$ tocoferol, seis horas antes do procedimento (CHIEN et al., 1997).

\section{Patogenia da injúria renal aguda}

A patogenia da IRA é complexa (MONAGHAN et al., 2012) e não totalmente compreendida (BELCHER et al., 2011). É dividida em quatro estágios: iniciação, extensão, manutenção e recuperação (MONAGHAN et al., 2012).

\section{Estágio 1: Iniciação}

O insulto ao tecido renal origina a primeira fase da síndrome. A duração desse estágio varia de horas até alguns dias, tempo necessário para que haja 0 declínio na TFG, sem a presença de sinais clínicos. Independente da causa da injúria inicial ocorre lesão das células tubulares e indução de isquemia. O quadro hipoxêmico instala-se até que haja o completo esgotamento das reservas de ATP (trifosfato de adenosina). O efeito é mais expressivo nas células no segmento S3 dos túbulos contorcidos proximais e ramo ascendente da Alça de Henle, pela baixa tensão de oxigênio quando comparadas ao resto do rim. Baixas concentrações de ATP aumentam o cálcio intracelular que ativam proteases e fosfolipases. Espécies reativas de oxigênio e radicais livres são então produzidos, deflagrando dano celular. 
Em resposta, inicia-se uma reação inflamatória renal com produção de citocinas e quimiotáticos (MONAGHAN et al., 2012).

A resposta inflamatória tenta proteger o rim da injúria, porém, desencadeia efeitos deletérios como a exposição do citoesqueleto das células tubulares. Há a perda da função de absorção por lesão dos micróvilos apicais da borda em escova. Além disso, há a perda de polaridade das bombas de $\mathrm{Na}^{+} / \mathrm{K}^{+}$e migração das glicoproteínas da posição normal na membrana celular (basolateral) para o citoplasma e membrana apical devido à perda da capacidade de ancoramento do citoesqueleto. Como resultado, o sódio aumenta na mácula densa do túbulo distal. O feedback túbulo-glomerular é ativado e, consequentemente, vasoconstrição arteriolar aferente agrava ainda mais a isquemia renal. A mudança na posição das glicoproteínas nas células tubulares faz com que haja a perda de conexão intercelular e as células se desprendem para o interior luminal tubular (MONAGHAN et al., 2012). A descamação intensa contribui para a obstrução do lúmen, consequentemente o filtrado vaza para o interstício peritubular e aumenta a pressão glomerular o que diminui a TFG (DEVARAJAN, 2006).

\section{Estágio 2: Extensão}

O segundo estágio da IRA é o de extensão no qual, há a amplificação do insulto inicial (SUTTON et al., 2002). Acredita-se que esse estágio tem duração de um a dois dias, visto que as células tubulares apresentam em apoptose e necrose, ocasionando redução progressiva da TFG. Os mecanismos que culminam com a injúria celular continuam, entretanto a disfunção endotelial com mudança de polaridade e descamação celular parece ter o papel principal nesta fase (MONAGHAN et al., 2012).

A injúria às células do endotélio peritubular exacerbam vasoconstrição e reduzem a reatividade aos agentes vasodilatadores, agravando a isquemia e a hipóxia. Os mediadores $P$ e E-selectinas na superfície celular e a molécula de adesão intercelular 1 (ICAM-1), que promovem a interação leucocitária com as células endoteliais renais, aumentam a expressão dos mediadores que, consequentemente, exacerbam a ativação de mais leucócitos. A cascata inflamatória torna-se intensa com congestão vascular e agravamento da isquemia (MONAGHAN et al., 2012).

O dano tubular torna-se intenso e é nesta fase que se propõe intervenção terapêutica para impedir que o dano celular continue. A duração deste estágio é curta e, devido à falta de ferramentas diagnósticas que sejam capazes de detectar os estágios 1 e 2, a injúria progride para o estágio 3 (MONAGHAN et al., 2012).

\section{Estágio 3: Manutenção}

Nesta etapa, a TFG alcança sua taxa mais baixa e se estabiliza. Estimase que esta etapa dure entre uma a duas semanas. A apoptose continua, o fluxo sanguíneo e reparo tecidual retornam à normalidade. Há o início do último estágio da cascata de inflamação, com proliferação e migração de células tubulares para o reestabelecimento da polaridade e integridade tubular. Complicações urêmicas são mais evidentes nesta fase (MONAGHAN et al., 2012).

\section{Estágio 4: Recuperação}

A TFG tem aumento superior durante a fase de reparo tecidual que durante o estágio 3. Esta pode se reestabelecer ou continuar baixa, resultando em 
doença renal crônica (DRC). A poliúria pós IRA parece ser um marcador inicial desta etapa de recuperação, podendo durar semanas até meses. Para a completa remissão do dano agudo, é essencial garantir que novas injúrias renais não acometam o parênquima (MONAGHAN et al., 2012).

\section{Sinais clínicos}

Os sinais clínicos de IRA são inespecíficos e podem incluir letargia, depressão, inapetência, vômito e diarreia. Polidpsia, poliúria ou anúria são os relatos mais comuns feitos pelo tutor. No exame físico, os achados podem variar de acordo com a etiologia. Pode ser constatado também a perda de massa muscular e peso, associados à falta de ingestão alimentar e má absorção intestinal (MEAK, 2003).

\section{Tratamento}

O tratamento suporte deve ser agressivo e baseado na correção do equilíbrio hidroeletrolítico e ácido-base (ROSS, 2011). A fluidoterapia tem papel significativo no tratamento da IRA por auxiliar na correção da perfusão renal e aumentar o fluxo sanguíneo renal (MEAK, 2003). A terapia específica somente é instituída quando a etiologia é conhecida (ROSS, 2011). Deste modo, o tratamento eficaz da IRA é dependente do diagnóstico laboratorial precoce aliada ao estabelecimento da etiologia para garantir que a estratégia terapêutica seja capaz de reestabelecer a função antes que a lesão produza danos renais permanentes (BELLOMO et al., 2012).

\section{Avaliação laboratorial do paciente com IRA}

As anormalidades clínicas da IRA não são evidentes nos dois estágios iniciais e, a forma de diagnosticá-la é dependente da confirmação laboratorial. $\mathrm{Na}$ fase 3 ou fase de manutenção, o diagnóstico laboratorial apenas tem função em guiar o clínico quanto à melhor forma de tratamento, visto que a confirmação baseiase no quadro de azotemia e/ou uremia apresentados pelo animal (ROSS, 2011).

\section{Exames tradicionais}

As ferramentas diagnósticas bioquímicas utilizadas na medicina veterinária para a detecção da insuficiência renal compreende o estabelecimento da azotemia pela análise conjunta dos valores de ureia e creatinina séricas. A disfunção renal é detectada por este tipo de avaliação, mas esses exames não avaliam a integridade renal (MEAK, 2003).

A creatinina sérica é um indicador mais específico para lesão renal que a ureia, uma vez que sofre menos influência de fatores extrarrenais. Todavia, é relevante reafirmar que aumentos nos valores séricos de creatinina ocorrem apenas quando $75 \%$ dos néfrons estão acometidos com o paciente azotêmico persistente (DIBARTOLA, 2011; HSU et al., 2014).

A regulação de eletrólitos, excreção de excesso ou manutenção mediante deficiências, é feita pelo rim. Os eletrólitos como o fósforo e o potássio são filtrados pelo glomérulo e reabsorvidos por mecanismos específicos localizados no túbulo contorcido proximal, alça de Henle e túbulo contorcido distal. $\mathrm{Na}$ avaliação da excreção fracionada desses eletrólitos é conferida a capacidade da função tubular renal (RIVERS et al., 1996), por meio do cálculo entre o percentual que é excretado em relação à concentração eletrolítica sérica do mesmo, e é feita a correção 
baseada na taxa de filtração e na excreção constante de creatinina (REINE \& LANGSTON, 2010).

A melhor forma de avaliar os eletrólitos é por determinação na urina ao longo de 24 horas, mas este teste na veterinária é considerado inviável. Não há um valor de referência definido para cães e gatos, mas, como regra geral, a excreção fracionada de sódio deve ser menor que 1\% (RIVERS et al., 1996) e potássio menor que 25\% (PRESSLER, 2013). A elevação do fósforo e do potássio está relacionada à redução da TFG (ROSS, 2011), no entanto estes dois eletrólitos podem estar dentro dos valores de referência em IRA. Apesar da injúria ao néfron, a excreção e a reabsorção continuam por compensação dos néfrons que ainda não estão lesionados e dos parcialmente afetados (PRESSLER, 2013). A hipercalemia pode ser observada em animais na fase de anúria e oligúria da IRA ou na desidratação severa (ROSS, 2011).

A mensuração da concentração das proteínas urinárias avalia a função glomerular e tubular e tem sido usada rotineiramente na medicina veterinária. $\mathrm{O}$ aumento significativo da concentração de proteína na urina serve como diagnóstico na detecção inicial e confirmação da doença renal. A proteinúria ainda auxilia na avaliação da eficácia terapêutica e progressão da doença (FORTERRE et al., 2004; PRICE et al., 2005).

Para essa avaliação, o ideal também seria ter a quantificação ao longo de 24 horas. Uma opção a esse método é o cálculo da razão proteína/creatinina urinárias (PU/CU). A avaliação considera que a creatinina é produzida e filtrada em uma taxa constante em animais hígidos e não submetidos à atividade física. Ao aplicar-se o índice, estabelece-se a relação entre a creatinina e a outra variável, neste caso a proteína, de modo que concentrações elevadas da proteína elevarão o valor estabelecido para a razão, indicando proteinúria patológica, cuja origem e peso molecular devem ser investigados. Entretanto, é importante ressaltar que este parâmetro somente pode ser considerado quando o sedimento urinário está inativo (REGO et al., 2011). Em pacientes hígidos, até $150 \mathrm{mg}$ de proteína por dia é considerado um achado normal (SODRE et al., 2007). De acordo com a International Renal Interest Society (IRIS) considera-se que, para cães e gatos, a razão de proteína na urina seja menor que 0.2 (não-proteinúricos) e os valores limites para cão entre 0,2 a 0,5 e para gatos entre 0,2 a 0,4 e valores acima destes citados confirmam a proteinúria (BROWN, 2013).

No exame de urina, alguns achados são considerados anormais e devem ser melhor investigados. A detecção de glicosúria moderada no exame químico, pode estar relacionada com lesão tubular (BELLOMO et al., 2012). O sedimento urinário deve ser analisado para verificar a presença de hemácias, leucócitos e cilindros e quantificá-los (ROSS, 2011). A avaliação do sedimento urinário especialmente com presença de cilindros, e a determinação da gravidade específica (densidade) urinária podem auxiliar no diagnóstico de IRA, apesar destes parâmetros carecerem de sensibilidade e especificidade (DE LOOR et al, 2013). O pH urinário é normalmente ácido para carnívoros, mas pode se apresentar alcalino caso haja crescimento bacteriano em infecções do trato urinário (ROSS, 2011).

\section{Diagnóstico laboratorial precoce da IRA}

A definição de biomarcador ou marcadores biológicos consiste na medida laboratorial que é capaz de refletir determinada função normal, alterações fisiológicas ou uma resposta à um agente farmacológico. Os marcadores biológicos 
podem ser fisiológicos por avaliar o funcionamento de um órgão, histológicos e anatômicos. Células específicas, moléculas, genes, enzimas ou hormônios podem ser biomarcadores (KATZ, 2004).

$\mathrm{Na}$ clínica, os biomarcadores auxiliam no diagnóstico ou na identificação do risco de uma doença, além de ser capaz de estratificar doentes, avaliar a gravidade ou progressão e definir ou auxiliar na monitoria de um determinado tratamento. Agências reguladoras como a Food and Drug Administration (FDA), os utilizam como ferramentas de aprovação de novos fármacos (KATZ, 2004).

$\mathrm{Na}$ medicina, os biomarcadores são classificados como marcadores de história natural de doença (tipo 0), marcadores de atividade de fármacos (tipo 1), e os surrogate makers (tipo 2). Um marcador do tipo "surrogate" é definido como a medida laboratorial ou sinal físico usado em ensaios terapêuticos como substituto para sinais clínicos, funções, sobrevivência e predição do efeito da terapia. A diferença entre um biomarcador e um surrogate marker é que o biomarcador é um candidato a surrogate marker, visto que este último já é um teste validado como um medidor dos efeitos de um tratamento específico (KATZ, 2004).

\section{Caracterização do biomarcador ideal para a detecção da IRA}

Nos últimos dez anos, o desenvolvimento de biomarcadores capazes de estabelecer o diagnóstico precoce de IRA foi estabelecido como pesquisa prioritária pela Sociedade Americana de Nefrologia (KOVALINKA, 2014). Um marcador precoce de IRA precisa ser capaz de identificar o risco de desenvolvimento da injúria; permitir o diagnóstico antes que as alterações possam ser detectadas pelos marcadores tradicionais; estratificar pacientes baseado em seus prognósticos e ser capaz de identificar a parte do néfron acometida (DE LOOR et al., 2013; KOVALINKA, 2014).

A mesma preocupação tem sido apontada pela IRIS, que define os diferentes estágios da IRA em cães e gatos. O estágio I consiste em animal não azotêmico, mas com histórico, clínica (diminuição de produção de urina responsiva à fluidoterapia) ou evidência laboratorial (glicosúria, cilindrúria, proteinúria, sedimento inflamatório ou anúria) de IRA apresentando oligúria ou não. Neste estágio inicial, o animal possui aumento nos valores séricos de creatinina maiores que $0.3 \mathrm{mg} / \mathrm{dL}$, dentro da faixa não-azotêmica, em um intervalo de 48 horas. O estágio II compreende animais com IRA, confirmada com azotemia moderada aliada ao histórico, alterações anatômicas ou na produção de urina (menor que $1 \mathrm{~mL} / \mathrm{kg} / \mathrm{h}$ dentro de seis horas) com creatinina sérica maior que $0.3 \mathrm{mg} / \mathrm{dl}$ durante um intervalo de 48 horas. Os estágios III (creatinina sérica entre $2.6-5.0 \mathrm{mg} / \mathrm{dL}$ ), IV (creatinina sérica entre 5,1 - 10,0mg/dL) e $V$ (creatinina sérica maior que $10,0 \mathrm{mg} / \mathrm{dL}$ ) compreendem animais com IRA confirmada e lesão do parênquima, aumento na severidade da azotemia e falha da função renal. Nestes estágios, quanto a produção de urina, o animal pode ser classificado como oligoanúrico (produção menor que $1 \mathrm{~mL} / \mathrm{kg} / \mathrm{h}$ ou sem produção urinária em tempo superior a seis horas) e não oligúrico (produção maior de $1 \mathrm{~mL} / \mathrm{kg} / \mathrm{h})$ (BROWN, 2013).

Os novos marcadores de IRA precisam ser de custo acessível, apresentar acurácia, ser de fácil mensuração, além de ser suficientemente sensível para detectar o início e severidade da injúria, iniciando o tratamento seja o mais precocemente possível. Tais características facilitam a intervenção médica e tornam viável avaliar a efetividade do uso dos agentes terapêuticos (BELCHER et al., 2011). 
Adicionalmente, o biomarcador deve ser endógeno, não tóxico, filtrado livremente pelo glomérulo e excretado sem alteração pelos rins (LIMA et al., 2014).

Acredita-se que nenhum dos novos biomarcadores será capaz de satisfazer todos os critérios de exigência, visto que um único marcador sozinho teria que ter acurácia para estimar a TFG e indicar a natureza de injúria renal ao mesmo tempo (LIMA et al., 2014).

\section{Divisão proposta para os biomarcadores}

As primeiras alterações causadas pela IRA são estruturais. Desta forma, marcadores que consigam detectar injúrias que alterem a composição morfológica renal estão sendo estudados pois parecem ser os mais precoces (BELCHER et al., 2011). Existe uma divisão dos novos biomarcadores em dois grupos (KOVALINKA, 2014). O primeiro grupo de biomarcadores foi separado pela capacidade de detectar danos morfológicos ou de indicar se há o infiltrado de células do sistema imunológico no túbulo renal, entre estes estão a lipocalína gelatinase associada ao neutrófilo e a proteína 7 de fator de crescimento. O segundo grupo refere-se às proteínas e enzimas possíveis de serem detectadas na urina provenientes de células tubulares que perderam a integridade morfológica como $y$-glutamil-transpeptidase, $\alpha$ -glutationa-s-transferase, n-acetil- $\beta$-glucosaminidase, myo inositol oxigenase, cistatina C, molécula de injúria renal 1, dentre outros (KOVALINKA, 2014).

Há uma segunda caracterização proposta na literatura considerando a melhor função desempenhada pelo biomarcador, no qual estudos indicam que a cistatina $C$ sérica, a interleucina-18 (IL-18) urinária e a molécula de injúria renal-1 (RIM-1) urinária parecem ser os melhores marcadores para o diagnóstico diferencial de IRA e DRC. Para o diagnóstico precoce sugere-se o uso de cistatina $C$ sérica, lipocalína gelatinase associada ao neutrófilo (NGAL), IL-18, glutationa-S-transferase e glutationa-P-transferase. Para predição de mortalidade, a molécula de injúria renal 1 (RIM-1) e a $\mathrm{N}$-acetil- $\beta$-D-glicosaminidase urinária parecem ser eficientes. Entretanto, há a necessidade de estudos que validem esses biomarcadores quanto à separação em grupos a fim de que haja a substituição dos métodos tradicionais pelos novos métodos disponíveis (COCA et al., 2008).

\section{Desenvolvimento de novos biomarcadores urinários na IRA}

O desenvolvimento de um novo candidato a biomarcador que avalie precocemente a IRA está baseado em duas hipóteses. A primeira fundamenta-se na fisiopatogenia da doença. A barreira normal de filtração glomerular em condições fisiológicas, não permite a passagem de proteínas com tamanho superior ao da albumina, com $69 \mathrm{kDa}$. Além disso, a carga da proteína também é capaz de influenciar na filtração, pois sabe-se que proteínas carregadas positivamente passam pela barreira glomerular mais facilmente quando comparada às proteínas contendo carga negativa. Consequentemente, alterações na estrutura e composição da barreira ou estado hemodinâmico do paciente poderiam ser fatores que alteram a permeabilidade e seletividade do glomérulo, resultando em grande quantidade de proteína detectável no ultrafiltrado (DE LOOR et al., 2013).

Fisiologicamente as proteínas, menores que a albumina, são filtradas livremente pelo glomérulo e em seguida são reabsorvidas pelos túbulos proximais. A proteinúria pode ser o resultado tanto da lesão glomerular, cursando com proteínas na urina de peso molecular alto, baixo e intermediário, como também de lesão tubular, que acarreta na urina presença de proteínas de peso molecular baixo e 
intermediário. Tanto na disfunção tubular secundária quanto na primária também vão aparecer na urina as enzimas presentes no citoplasma das células tubulares (DE LOOR et al., 2013).

Disfunções primárias do glomérulo e disfunções secundárias ou primárias dos túbulos ocasionam incapacidade dos túbulos em reabsorver a totalidade das proteínas que passaram pela barreira glomerular lesionada ou não, o que culmina em proteinúria. Em casos de sobrecarga tubular, a afinidade dos receptores tubulares do megalina e cubilina em relação as proteínas do ultrafiltrado, se altera, resultando em extravasamento das mesmas na urina. A proteinúria é normalmente detectável no exame de urina e sua detecção é o início da cascata progressiva de perda da função renal (DE LOOR et al., 2013). Concentração urinária de proteína acima de $0,5 \mathrm{~g}$ em 24 horas, é um marcador de severidade do dano tubular, do risco de fibrose túbulo-intersticial e consequentemente ainda prediz se a injúria pode tornar-se crônica (KEPLA et al., 2013).

A segunda hipótese que subsidia a detecção de novos marcadores considera as técnicas para detecção genômica de proteinúria e peptídeos na urina. Estas técnicas permitiram aperfeiçoar as pesquisas em humanos, mas na medicina veterinária, raramente são utilizadas na pesquisa de marcador precoce. $\mathrm{Na}$ veterinária, as técnicas utilizadas consistem da espectrofotometria, que permite identificar a proteína ligadora de retinol, a eletroforese que possibilita a determinação do peso molecular das proteínas e o western blot que possibilita a identificação da proteína. Todas estas técnicas são aplicadas na urina e possibilitam a classificação da lesão em glomerular ou tubular (DE LOOR et al., 2013).

A aplicação na rotina da clínica veterinária dos novos biomarcadores renais tem encontrado alguns entraves, como a validação das técnicas e reagentes utilizados para seres humanos, para os animais de companhia. Além disso, alguns marcadores pesquisados podem ter alterações nas concentrações não ligadas às causas renais; desse modo o estabelecimento dos valores de normalidade para as diferentes espécies é fundamental na interpretação dos resultados. Adicionalmente, as técnicas laboratoriais empregadas, na maioria dos casos, são caras e de difícil execução na rotina da clínica veterinária (DE LOOR et al., 2013).

\section{Biomarcadores séricos e urinários para IRA}

Os biomarcadores são capazes de localizar a injúria ou perda da função de uma região lesionada. Por exemplo, a proporção de proteínas de alto à baixo peso molecular na urina pode ser usada para distinguir um dano tubular de um dano glomerular. A microalbuminúria é geralmente usada como um indicador de disfunção glomerular enquanto que a excreção de transferrina indica dano severo. Proteínas de baixo peso molecular, como a beta-microglobulina, proteína ligadora do retinol e alfa-microglobulina que refletem o dano tubular. Injúrias na região proximal tubular têm como indicadores as enzimas lisossomais $\mathrm{N}$-acetil- $\beta$-D-glicosaminidase (NAG) e enzimas da borda em escova (alanino aminopeptidase). As isoenzimas a glutationas-transferase refletem a injúria ao túbulo proximal enquanto que a glutationa-stransferase denota o dano na região do túbulo distal. Adicionalmente, as isoenzimas da NAG podem ser usadas para distinguir dano glomerular da lesão tubular (PRICE, 2002).

\section{$\mathrm{N}$-acetil-beta-d-glicosaminidase (NAG) e $\mathrm{y}$ - glutamil-transpeptidase (GGT)}


A NAG (150kDa) (DE LOOR et al., 2013) e a GGT são enzimas dos túbulos proximais e, em humanos, foram relatadas como excelentes marcadores para detecção de IRA. A enzimúria pode refletir disfunção tubular aguda (COBRIN et al., 2013).

A atividade da NAG pode ser subdividida em isoenzimas: NAG A e que associada à proteína tubular e à atividade lisossomal. A NAG B é mais indicativa de dano tubular. Fisiologicamente, pequenas quantidades de ambas as enzimas são excretadas na urina; quando há disfunção tubular ocorre aumento significativo desses níveis (COBRIN et al., 2013). Em humanos, GGT tem-se mostrado útil como marcador precoce de nefrotoxicidade. Esta enzima está presente na borda em escova dos túbulos contornados proximais renais e o aumento na excreção da GGT urinária é diagnóstico de lesão ou disfunção tubular renal (HAYES \& GOLDENBERG, 1963; REMUZZI et al., 1997). Estudos na medicina veterinária tiveram ótimos resultados com NAG e GGT e ambos podem ser usados para a detecção de injúria tubular (COBRIN et al., 2013).

A atividade da NAG e a GGT é determinada por métodos enzimáticos colorimétricos com leitura em espectrofotometria (COCA et al., 2008). Quanto à função, a NAG é usada para avaliação de função tubular e apresentou-se elevada em doenças renais secundárias a outras doenças. Para caninos, a NAG teve aumento significativo antes do aumento de creatinina (ZHOU et al., 2014).

A IRA associada à piometra e à leishmaniose levou a aumentos de NAG. Elevação da atividade sérica de NAG também foi associada à artrite reumatóide em cães (ZHOU et al., 2014). A NAG urinária foi capaz de auxiliar no prognóstico da IRA (COCA et al., 2008).

A enzima GGT urinária em cães aumentou em casos de IRA quando comparados a animais saudáveis, porém sem aumento significativo na comparação entre animais com DRC e animais saudáveis (COBRIN et al., 2013). Em outro estudo, que comparou a atividade urinária de GGT em cães saudáveis e portadores de DRC foi observado que, nos doentes renais, a atividade da enzima foi significativamente superior à dos cães saudáveis (SOUSA, 2011). Na glomerulonefrite induzida em gatos, a NAG aumentou devido à proteinúria. $A$ quantificação da NAG não foi capaz de predizer o desenvolvimento de azotemia em gatos geriátricos ou com hipertireoidismo e DRC (COCA et al., 2008).

\section{Fosfatase alcalina (ALP), $\alpha$-glutationa-s-transferase e n-acetil- $\beta$-D- glucosaminidase}

Quando há lesão da borda em escova do túbulo contorcido proximal ocorre diminuição da reabsorção e aumento da excreção de várias proteínas de baixo peso molecular normalmente filtradas, tais como a fosfatase alcalina e a alanina amino-peptidase. A razão entre essas enzimas e a creatinina urinária tem sido utilizadas para detectar precocemente injúria renal aguda (PRICE, 2002).

A a-glutationa-s-transferase e n-acetil-b-glucosaminidase são fosfatases alcalinas armazenadas em organelas intracelulares liberadas na urina sob condições de injúria. Há uma problemática envolvendo esses dois biomarcadores, que são grandes variações nos valores em pacientes humanos que apresentavam doenças concomitantes. Tais variações podem estar relacionadas ao fato de que não são enzimas específicas do rim e, consequentemente, as propriedades analíticas podem variar de acordo com o tipo de insulto e, desta forma, até o momento, demonstram inviabilidade na utilização em rotina da clínica médica (KOVALINKA, 2014). 


\section{Lipocalína gelatinase associada ao neutrófilo (NGAL)}

A lipocalína gelatinase associada ao neutrófilo (NGAL) tem sido o biomarcador mais estudado na medicina para a detecção precoce da IRA e tem sido considerada um marcador promissor para o auxilio no tratamento de pacientes com IRA (ANGELETTI et al., 2016). A NGAL possui 25kDa (XUE et al., 2014; ALGE \& ARTHUR, 2015) e é sintetizada por células tubulares, neutrófilos e outros tipos celulares de outros órgãos (KOVALINKA, 2014). É também excretada pelas células do ramo ascendente da Alça de Henle e ductos coletores na urina (KEPLA et al., 2013). A NGAL está na circulação e é filtrada pelo glomérulo e reabsorvida pelas células epiteliais tubulares (KOVALINKA, 2014).

Este biomarcador é importante para o transporte de pequenas moléculas hidrofóbicas, as sideróforas (KOVALINKA, 2014). Inicialmente, é liberado por neutrófilos ativados no sítio da agressão e funciona como um marcador de fase aguda indicativo da injúria inflamatória (BELCHER et al., 2011).

Durante a IRA, a expressão da NGAL nos túbulos é exacerbada, podendo ser mensurada na urina. Outra característica da NGAL consiste na precocidade visto que o aumento ocorre antes da observação dos efeitos clínicos iniciais da IRA (KOVALINKA, 2014). No rim isquêmico ou em intoxicações, mensageiros de NGAL mRNA são rapidamente regulados, horas após o dano tubular (COBRIN et al., 2013).

Estudos pré-clínicos em humanos concluíram que a NGAL mostrou-se detectável em amostras sanguíneas e urinárias assim que a injúria foi iniciada (XUE et al., 2014). Além disso, parece ser facilmente medida no plasma ou soro, pela técnica de ELISA, com uso de anticorpos monoclonais (COBRIN et al., 2013). A atividade urinária da NGAL é também facilmente mensurável, podendo servir como biomarcador urinário (BELCHER et al., 2011). ELMAS et al., 2016 relatam que NGAL urinária foi sensível, precoce e não invasivo cujo aumento urinário foi significativo em animais não sépticos na identificação da IRA em neonatos humanos em estado crítico.

Novos ensaios em humanos têm sido realizados para o desenvolvimento de um teste rápido utilizando amostras plasmáticas e urinárias (COBRIN et al., 2013). Tem sido estudada em pacientes humanos submetidos a cirurgias na artéria coronária para realização de ponte de safena para predizer o risco de desenvolvimento de IRA (JAIN et al., 2016). Estima-se que o custo varie entre 5 a 20 libras por teste (em torno de 80 reais) (BELLOMO et al., 2012).

Em cães, o teste de ELISA foi validado para quantificar a NGAL na urina. Quando utilizado em pacientes com nefropatias congênitas, teve maior precocidade que a creatinina sérica (PRESSLER, 2013). A NGAL obteve os mesmos resultados que outros marcadores como a $\beta$-microalbumina e a NAG na avaliação da TFG em pacientes com fibrose renal (COBRIN et al., 2013). Ensaio específico canino para dosagem de atividade urinária de NGAL estão disponíveis apenas para fins experimentais (BioPorto Diagnostics, Gentofte, Dinamarca) (PRESSLER, 2013). Cães azotêmicos apresentaram atividade plasmática e urinária aumentadas quando comparados a animais saudáveis. O teste plasmático pareceu auxiliar na diferenciação entre IRA e DRC em cães com azotemia. Quanto à sensibilidade da NGAL, o teste plasmático pareceu ser menos sensível que o teste urinário (STEINBACH et al., 2014). 
Em testes com Beagles induzidos à toxicidade tubular proximal pelo uso de gentamicina, a NGAL urinária foi mais sensível quando comparada à NAG. O estudo concluiu que este biomarcador pode, futuramente, ser aplicado clinicamente para constatação da IRA mediante a não-invasividade (ZHOU et al., 2014). Um segundo estudo com indução de nefrotoxicidade por gentamicina, também com Beagles, revelou que a molécula de injúria renal 1 (RIM-1), proteína ligadora de ácido graxo hepático (L-FABP) e NGAL tem-se apresentado como as melhores ferramentas no diagnóstico e prognóstico de IRA (SASAKI et al., 2014).

Quando comparado a outros biomarcadores, a NGAL teve desempenho superior a NAG, a -microalbumina e creatinina sérica. Entretanto, essa enzima não foi capaz de predizer possibilidade de mortalidade em pacientes humanos com IRA (COBRIN et al., 2013). Quando associada à molécula RIM-1, foi possível predizer o resultado da diálise e mortalidade em pacientes humanos de UTI (Ren Ji Hospital/Xangai/China). Verificou-se que a combinação desses dois marcadores foi excelente para predizer o desenvolvimento de IRA com $90 \%$ de sensibilidade e $100 \%$ de especificidade, quando comparado com o uso de apenas um marcador. $A$ utilização associada de NGAL com IL-18 como biomarcadores para o diagnóstico e prognóstico de IRA em pacientes humanos críticos também parece ser uma associação viável, visto a complementariedade dos marcadores (XUE et al., 2014).

Aumentos de NGAL urinária foram detectados em $100 \%$ dos pacientes submetidos à cirurgia cardíaca, $2 \mathrm{~h}$ após o término, indicando a eficiência para diagnosticar a IRA. O biomarcador mostrou acurácia moderada para detectar IRA 24 horas após a cirurgia e foi um excelente marcador em especificidade, mas a sensibilidade para o diagnóstico precoce foi baixo (COCA et al., 2008). Entretanto, para outros autores parece ser o melhor marcador diagnóstico em estudo das doenças renais e o mais promissor para o diagnóstico de IRA (KEPLA et al., 2013).

\section{Cistatina C}

A cistatina $\mathrm{C}$ é uma cisteína do tipo inibidora de protease (KEPLA et al., 2013). Todas as células nucleadas parecem produzir a cistatina $C$, uma protease inibidora de 13kDa (DE LOOR et al., 2013) que é filtrada e absorvida pelo receptor megalina, localizado nas células epiteliais tubulares proximais, local de degradação (KOVALINKA, 2014). É removida pelo glomérulo e reabsorvida pelos túbulos renais e então, metabolizada e não volta para a circulação (LIMA et al., 2014). O padrão normal das concentrações urinárias de cistatina $C$ está entre 0,03 a $0,3 \mathrm{mg} / \mathrm{L}$ e 0 aumento de cistatina sérica é proporcional à queda na TFG (KEPLA et al., 2013).

A detecção da cistatina $C$ na urina é um achado anormal (DE LOOR et al., 2013), indicador de deficiência na absorção e degradação pelas células epiteliais tubulares proximais. A constatação positiva desta enzima na urina faz com que a cistatina $C$ seja um potencial biomarcador para IRA por especificar o local (células epiteliais tubulares) e, mediante uma lesão tubular mínima, pode levar ao extravasamento, demonstrando alta sensibilidade (KOVALINKA, 2014).

Outros autores consideram que a menor variabilidade nas determinações sanguíneas da cistatina $\mathrm{C}$, a meia-vida mais curta e o menor volume de distribuição a tornam um marcador de função glomerular com maior sensibilidade para detectar diminuições leves da TFG na DRC do que a creatinina e outras moléculas de baixo peso molecular. É importante salientar que ocorre aumento da cistatina $C$ na presença de leve diminuição da TFG, na chamada "faixa cega" da creatinina. Adicionalmente, estudos recentes mostraram que a cistatina $C$ se eleva 
precocemente na IRA, fato que pode ser observado em pacientes internados em unidades de tratamento intensivo, após transplante hepático, cirurgia cardíaca, quimioterapia com cisplatina, angiografia cardíaca, após uninefrectomia e na progressão da nefropatia diabética (ABENSUR, 2014). Os valores de cistatina $C$ no soro podem ser afetados pelo sexo, altura, peso, diabetes, uso de corticosteróides, função anormal de tireóide e inflamação sistêmica (LIMA et al., 2014). Constatou-se uma variação de $37 \%$ nos valores de referência quando a concentração alterou-se em decorrência de fatores extrarrenais o que pode ter sido um fator complicador na interpretação dos resultados (COBRIN et al., 2013). No entanto, pareceu ter boa qualidade e acurácia para o diagnóstico precoce de IRA com 24 a 48h, pois foi capaz de ser detectada laboratorialmente por meio de amostras sanguíneas antes da constatação clínica de IRA (COCA et al., 2008).Também pode ser considerado um sensível marcador no paciente crônico (KOVALINKA, 2014).

A cistatina $C$ urinária em humanos obteve níveis séricos aumentados em pacientes críticos cuja IRA era pré-renal, evidenciando a lesão estrutural do parênquima (NEJAT et al., 2012). Em cães, a cistatina $C$ tem sido determinada com reagentes comerciais em imunoensaios turbidimétricos (PETIA), imunoensaios usando nefelômetros e ensaios contendo enzima ligadora imunoabsorvente (COBRIN et al., 2013). Com a técnica de western blot foi possível validar os estudos em animais, por meio de reação cruzada entre cistatina $C$ anti-humana e cistatina $C$ canina. As alterações nos valores da cistatina $C$ por fatores extrarrenais ainda são controversas, pois hipoteticamente fatores como peso e sexo podem afetar as concentrações de cistatina $C$ sérica e/ou urinária. Há carência de estudos que avaliem a cistatina $\mathrm{C}$ em cães e gatos com IRA (COBRIN et al., 2013).

Estudo recém-publicado com indução de toxicidade pelo uso da gentamicina em Beagles, mostrou que a cistatina $C$ urinária apresentou aumento diante da redução da TFG e precedeu os aumentos da ureia e creatinina sérica, além dos outros marcadores em teste: NAG, L-FABP e NGAL. Neste estudo ainda, concluiu-se que a cistatina $C$ urinária parece ser o melhor marcador do tipo endógeno para avaliar a TFG que a creatinina plasmática (SASAKI et al., 2014).

\section{Microglobulinas ( $\alpha$ - microglobulina e $\beta$-microglobulina)}

As microglobulinas são proteínas de baixo peso molecular, sendo que a a - microglobulina possui 27 kDa e a $\beta$-globulina possui 11,8 kDa. A a-microglobulina é uma proteína inflamatória que se liga aos linfócitos T e B (KEPLA et al., 2013), porém ambas são expressas em todas as células nucleadas (COBRIN et al., 2013).

$O$ aumento da concentração da $\alpha$-microglobulina na urina de pacientes humanos com necrose tubular aguda indica a necessidade de intervenção terapêutica e auxilia na definição do prognóstico da doença. Além disso, parece ser um indicador sensível para lesão tubular na região proximal (KEPLA et al., 2013).

A avaliação de ambas as globulinas pode ser feita por meio de ELISA e radioimunoensaio. A a-microglobulina tem sido associada a severas lesões histológicas em nefropatias membranosa e auxiliou na detecção da progressão da injúria para DRC (COBRIN et al., 2013).

Quanto às limitações, em urinas ácidas, a $\beta$-microglobulina é instável, impedindo a quantificação na urina. Adicionalmente, a produção no fígado em pacientes com doença hepática pareceu estar relacionada com a diminuição de concentração e, consequentemente, pode interferir na capacidade em detectar doença renal (COBRIN et al., 2013). A interpretação da $\beta$-microglobulina urinária 
pode ajudar na avaliação da rejeição de transplantes renais, mas deve ser avaliada com cuidado devido a pluralidade de fatores influenciando a concentração plasmática (KEPLA et al., 2013).

Os testes já validados em cães são western blot e ELISA e ambos parecem ter resultados mais acurados no monitoramento de DRC. Foram detectados aumentos das duas microglobulinas em cães com síndrome de Alport e com nefropatia ligada ao cromossomo X (COBRIN et al., 2013). A microglobulinas são marcadores inespecíficos de função renal (DE LOOR et al., 2013), capazes de detectar injúria tubular e glomerular, mas que não servem para separar quadros agudos de crônicos (KOVALINKA, 2014).

\section{Molécula de injúria renal 1 (RIM-1)}

É uma glicoproteína de membrana celular, de 104kDa (KEPLA et al., 2013), que possui transmembrana, citoplasma e ectodomínios. A expressão gênica e proteica não é detectada em rins saudáveis, mas são evidentes nas isquemias, no uso de drogas que causam injuria nefrotóxica e na função renal diminuída, decorrente de transplante renal em humanos (BELCHER et al., 2011). A expressão ocorre no túbulo proximal em níveis indetectáveis em rins normais. Apenas em resposta à injúria, o ectodomínio é extravasado para o lúmen do túbulo e, posteriormente, detectada na urina (BELCHER et al., 2011).

Por não ser expresso em um rim normal, considera-se um marcador extremamente específico na detecção de injúria em túbulos proximais (COBRIN et al., 2013). O papel exato de RIM-1 no processo fisiopatológico da lesão renal é ainda obscuro, no entanto, pelo menos na IRA, parece ter efeito benéfico envolvendo diferenciação, redução na formação de cilindros e obstrução tubular, ativação da fagocitose dos debris celulares oriundos da necrose e apoptose (BELCHER et al., 2011). Estudo com Beagles nefropatas, indicou que o RIM-1 tem um papel importante no estágio de regeneração das células tubulares, momento em que o órgão tenta reestabelecer a integridade e função (SASAKI et al., 2014).

O RIM-1 é um biomarcador capaz de discriminar necrose tubular aguda (NTA) de outras causas de IRA, incluindo nefrite intersticial aguda e fibrose (XUE et al., 2014), rejeição de transplante, nefropatia obstrutiva e azotemia pré-renal (BELCHER et al., 2011). Adicionalmente, é capaz de indicar a presença de nefrotoxicidade em exames pré-clínicos em humanos. Em 13 modelos experimentais caninos em que houve avaliação de RIM-1 urinária, creatinina sérica, ureia e NAG, o primeiro mostrou-se o biomarcardor mais sensível para identificar injúria tubular renal (XUE et al., 2014).

Na medicina, o European Medicines Agency (EMA), Pharmaceuticals and Medicals Devices Agency (PDMA) e a Food and Drug Administration (FDA), instituições certificadoras de novos fármacos para a produção em escala comercial, aprovaram a utilização da RIM-1 e da cistatina C urinária para a detecção da IRA, frente a novos fármacos em teste, a fim de assegurar baixa ou ausência de nefrotoxicidade (KAl et al., 2013). Em 62 humanos transplantados renais, a expressão da RIM -1 aumentou em todos os pacientes que apresentaram injúria tubular renal e em $92 \%$ dos pacientes que apresentaram rejeição do órgão. Os aumentos de RIM-1 urinário mostraram-se associados com a redução na taxa de filtração glomerular e parece ser um biomarcador confiável para IRA em pacientes humanos com nefropatia (XUE et al., 2014). 
Aumento de RIM-1 no tecido renal de humanos com necrose tubular aguda foi mais sensível que os métodos histopatológicos de rotina na identificação de injúria tubular renal. Aumentos nas concentrações também foram detectados em pacientes humanos portadores de DRC, mas com menos acurácia. Em pacientes internados, o aumento na concentração urinária parece ser capaz de predizer a necessidade de terapia suporte, podendo ser utilizado como fator de prognóstico (COBRIN et al., 2013).

Estudos comparativos mostram que RIM-1 urinário produz resultados modestos em predizer a mortalidade quando comparados aos métodos tradicionais de avaliação de severidade de doença. Em pacientes humanos e crianças em emergência, a IL-18 urinária parece ser o melhor marcador para prever mortalidade (LIMA et al., 2014). Em pacientes críticos com IRA pré-renal, cistatina C, IL-18 e RIM-1, apresentam concentrações significativamente aumentadas quando comparadas aos pacientes sem IRA (NEJAT et al., 2012).

RIM-1 foi detectado logo após a injúria renal, e os valores permaneceram elevados até a reparação do tecido tubular epitelial (XUE et al., 2014). Quanto aos animais de companhia, em gatos, estão em andamento alguns estudos usando RIM1 e parece que a molécula é um promissor marcador a ser utilizado nos animais de companhia (COBRIN et al., 2013).

\section{Interleucina 18}

A interleucina-18 (IL-18) é produzida tanto por células do sistema imunológico quanto do epitélio tubular. Os túbulos a secretam na urina após injúria isquêmica (KOVALINKA, 2014). Em humanos, para a detecção na urina, são utilizando reagentes comerciais, sendo considerado um teste fácil, rápido, eficiente e não oneroso (BELCHER et al., 2011).

A ativação da IL-18 se inicia por meio da caspase 1 que é uma protease do tipo cisteína pró-inflamatória intracelular (KEPLA et al., 2013). As concentrações séricas de IL-18 aumentam de quatro a seis horas após crianças serem submetidas às cirurgias cardíacas com circulação extracorpórea. O pico ocorre com 12 horas de cirurgia e permanece elevado até 48 horas pós-cirurgia. Os valores séricos da interleucina foram significativamente aumentados em comparação ao da creatinina sérica (BELCHER et al., 2011). As concentrações de IL-18 foram maiores em pacientes com necrose tubular (COCA et al., 2008).

Há relatos de que a IL-18 possui baixa sensibilidade e alta especificidade (COCA et al., 2008). No entanto, em humanos, os níveis urinários de IL-18 demonstraram sensibilidade e especificidade maior que $90 \%$ no diagnóstico de IRA já estabelecida (PARIKH et al., 2005). As elevações na urina raramente foram falso positivas (COCA et al., 2008).

Em estudos pré-clínicos em humanos, a IL-18 urinária confirmou o diagnóstico de IRA de forma eficiente em pacientes com infecções do trato urinário, injúria renal crônica e síndrome nefrótica. A IL-18 mensurada por ELISA mostrou-se capaz de confirmar a injúria nas primeiras 24 a 48 horas após lesão (XUE et al., 2014). A IL-18 associada a MIR-1 serviu para predizer a IRA com $72,7 \%$ de sensibilidade e $92,8 \%$ de especificidade em pacientes humanos com queimaduras graves (REN et al., 2015). Tanto a IL-18 como a NGAL não apresentam boa performance para predizer a severidade nem para classificar a IRA (COCA et al., 2008). 
A utilidade do IL-18 na detecção precoce de IRA tem sido investigada em vários segmentos médicos e os resultados têm sido positivos quando comparados à creatinina (BELCHER et al., 2011). Há escassez de estudos em cães e gatos, mas em humanos e ratos, já está estabelecida como marcador de injúria tubular e de doenças inflamatórias (COBRIN et al., 2013).

\section{Proteína ligadora do retinol (PLR) \\ É uma proteína de baixo peso molecular $(21 \mathrm{kDa})$ da família das} lipocalínas (KEPLA et al., 2013), sintetizada no fígado. E filtrada no glomérulo e quase que completamente reabsorvida e catabolizada nas células dos túbulos proximais. Tem como função fisiológica, o transporte de retinol (vitamina A). Tem fácil detecção na urina quando o interstício tubular está lesado, o que impede a reabsorção (DE LOOR et al., 2013).

Fisiologicamente, o complexo $\mathrm{PRL}$ liga-se à transtiretina, sendo responsável pelo transporte de tiroxina e retinol no plasma. A ligação impede a filtração deste pelo glomérulo, quando reabsorvido direciona-se para os tecidosalvos, onde a ligação entre PRL e transtiretina cessa. Adicionalmente, esta estrutura sem ligação com outras proteínas é filtrada pelo glomérulo e reabsorvida após ser catabolizada pelas células tubulares renais. $\mathrm{O}$ aumento na detecção de PRL urinário precede o desenvolvimento de microalbuminúria em pacientes humanos (DE LOOR et al., 2013).

Em humanos é mensurada por ELISA e parece ser um marcador sensível de dano tubular. Prediz a progressão de doença renal e auxilia no estabelecimento do prognóstico em pacientes com glomerulopatias e crianças com asfixia ao nascimento (COBRIN et al., 2013). Quando comparada à beta-microglobulina, parece ser um marcador melhor para dano de túbulo proximal (KEPLA et al., 2013).

Em ovelhas, foi detectada na urina, por meio de eletroforese, duas horas após indução de toxicidade por ketoprofeno, o que refletiu o dano tubular pelo uso do fármaco. Este achado sugere que a PRL pode ser utilizada como um marcador precoce, entretanto há a necessidade de mais estudos nesta espécie que validem a especificidade e sensibilidade em experimentos com 0 uso de fármacos nãoesteroidais que utilizem de superdosagem (PALVIAINEN et al., 2012).

A detecção desta proteína pode ser feita por meio de western blot e ELISA, e em cães com DRC produziram bons resultados, fato que possibilita a utilização como marcador urinário na diminuição da função tubular para esta espécie animal (DE LOOR et al., 2013). Em estudo comparando cães adultos e jovens com DRC ocorreram aumentos significativos quando comparado às concentrações de ureia e creatinina. $O$ fator idade parece não afetar os resultados encontrados para este marcador. Esteve significativamente aumentado em cães azotêmicos, mas não apresentou sensibilidade para detectar diminuição na TGF em cães não azotêmicos (COBRIN et al., 2013; DE LOOR et al., 2013). Mais estudos são necessários para predizer se é um marcador sensível de disfunção no túbulo proximal e taxa de filtração glomerular (COBRIN et al., 2013), bem como para avaliar resultados controversos no diagnóstico precoce de IRA (DE LOOR et al., 2013).

$O$ aumento da PRL em gatos com hipertireoidismo foi constatado quando comparado a gatos saudáveis. Entretanto, houve muitas variações individuais entre os pacientes estudados. Adicionalmente, um estudo em cães sugere que esta proteína parece ser eficaz na detecção de disfunção tubular nos estágios crônicos da doença renal (COBRIN et al., 2013). 


\section{Proteína 7 de fator de crescimento e ligação de insulina (IGFBP-7) e metaloproteinase inibidor de tecido 2 (TIMP-2)}

As proteínas IGFBP-7 e o TIMP-2, fisiologicamente estão envolvidas no término do ciclo celular que, mediante IRA, tem suas funções comprometidas (KOVALINKA, 2014). Estudo com pacientes humanos em estado crítico, indicaram que estes dois marcadores foram os melhores em predizer evolução da IRA. Foram usados em um painel e testados por meio de ELISA e do NephroCheck que consiste na multiplicação dos dois marcadores (TIMP-2 x IGFBP7) (KASHANI et al., 2013).

O TIMP-2 e IGFBP-7 foram capazes de distinguir pacientes em IRA dos saudáveis e mostrou bom desempenho em pacientes em sepse e pós-cirúrgico. Também possibilitaram localizar a injúria e a perda funcional do epitélio renal, bem como foram capazes de detectar a mudança da IRA no estágio 2 para o estágio 3 dentro de 12 horas. Quando comparados a outros marcadores em estudo: cistatina C, KIM-1, IL-18 e L-FABP na urina tiveram valores mais elevados que os demais (KASHANI et al., 2013).

\section{Mioinositol oxigenase (MIOX)}

O gene que codifica o MIOX mostrou-se ser específico de rins. A proteína MIOX pode representar um marcador valioso para injúrias renais em ratos e humanos in vivo, até o momento (KOVALINKA, 2014). Nos estudos da proteína MIOX, foi desenvolvido um imunoensaio para a quantificação de MIOX em ratos e em humanos. Os ensaios confirmaram que há especificidade entre os anticorpos por western blot e houve o mapeamento dos epítopos. Os resultados demonstraram que a proteína MIOX foi expressa apenas em rins humanos e que a expressão estava localizada nas células tubulares. Em outro ensaio em modelo murino para injúria renal isquêmica, os valores de MIOX sérica aumentaram dentro das 24 h pós-injúria quando esta foi mais significativa (KOVALINKA, 2014).

Em pacientes críticos humanos, MIOX foi detectada 54h antes do aumento de creatinina mas não foi possível estimar em tempo quando a injúria aconteceu. Quanto aos testes com MIOX plasmático, o exame permitiu separar pacientes oligúricos dos não oligúricos na IRA. Estudos com ratos tiveram expressão reduzida de mRNA MIOX em rins de ratos com IRA (KOVALINKA, 2014).

A proteína MIOX parece preencher todos os requerimentos para ser um marcador precoce, visto que tem aumento precoce em relação à creatinina sérica, além de possuir especificidade renal. A expressão só acontece nas células tubulares durante uma injúria renal e posteriormente é liberado na urina. Nesse sentido, é necessário estender os estudos da proteína MIOX em animais de companhia para constatar se poderá ser um marcador precoce viável e responder perguntas que ainda não foram respondidas sobre a expressão, concentrações no plasma e urina após injúria e o além do tempo de liberação (KOVALINKA, 2014).

\section{Proteína ligadora de ácido graxo hepático (L-FABP)}

A proteína ligadora de ácido graxo hepático (L-FABP) é um lipídeo intracelular localizado no rim, na região citoplasmática das células dos túbulos proximais. O L-FABP liga-se seletivamente a regiões livres e insaturadas de ácidos graxos e produtos lipídicos perioxidados, lipídeos em estresse perioxidativo e tecido injuriado por isquemia e reperfusão (BELCHER et al., 2011). 
O aumento na urina parece estar relacionado a danos hepáticos ou nas inflamações sistêmicas. Primeiramente foi relacionado também às injúrias tubulares na região proximal (BELCHER et al., 2011), bem como após danos por isquemia e reperfusão por transplante renal quando houve aumentos urinários da L-FABP após quatro horas em pacientes submetidos às cirurgias cardíacas (NEGISHI et al., 2009).

Com a mensuração do L-FABP foi possível prever injúrias teciduais com maior precisão que a ureia e NAG, além de ser detectada na urina mais rapidamente que ureia e mensurar o declínio da TFG, demonstrando sensibilidade e especificidade para IRA (BRAUN et al., 2003).

\section{CONSIDERAÇÕES FINAIS}

A possibilidade de construir um diagnóstico preciso para IRA na medicina veterinária torna-se promissor com a utilização dos novos biomarcadores. A aplicação experimental na medicina já é uma realidade, mas não para a veterinária. As técnicas empregadas provêm de ensaios laboratoriais de alto custo que exigem equipamento específico, outro entrave consiste na carência por reagentes espécie específicos, havendo a necessidade de validação dos testes humanos disponíveis para emprego em animais.

Em uma situação ideal, a integridade morfológica, a avaliação de função e a localização precisa da injúria deveriam ser informações fornecidas por um único marcador. Dentre os biomarcadores citados, nenhum pareceu ser capaz de atender tais exigências. Desta forma, fica evidente que a associação entre marcadores é a melhor opção para a criação de um painel diagnóstico precoce da IRA, pois a complementariedade de informações que fornecem, permitirão a avaliação completa do paciente.

Associações entre a NGAL e a RIM-1 parecem ser as melhores associações dentre os marcadores estudados experimentalmente em humanos. Estudos que comprovem esta eficácia nos animais de companhia, além do desenvolvimento de kits comerciais que possam viabilizar o seu uso clínico são necessários para sua futura aplicação na veterinária.

Outro marcador que merece ser melhor compreendido é a MIOX que, devido à sua expressão ser específica dos rins e possuir rápida constatação diagnóstica parece atender às características de um marcador ideal. A MIOX é um marcador promissor, porém poucos trabalhos em humanos ratificam seus resultados benéficos e, até então, não há nenhum trabalho publicado na medicina veterinária.

Dentre os biomarcadores apresentados, a cistatina $\mathrm{C}$ tem sido mais relatado em estudos na medicina veterinária devido ao fato de que a técnica já foi validade na experimentação em animais, ser menos custoso entre os demais e reagentes comerciais de preço acessível. É importante salientar que estudos com este marcador são extremamente recentes e, por isso, ainda não há um número significativo de trabalhos em cães e gatos que apresentem resultados do seu uso no diagnóstico precoce de IRA.

A avaliação da urina como amostra para o diagnóstico da IRA fica evidente após a presente revisão. Há a necessidade de conscientizar o médico veterinário da precocidade de informações presentes no exame de urina quando comparadas às avaliações séricas atualmente empregadas. As alterações morfológicas urinárias são rapidamente constatadas, visto que enzimas se exacerbam na urina no pós-injúria ou são achados incomuns na urina. As alterações 
séricas são tardias e podem prejudicar a remissão completa do paciente caso este seja o único critério de avaliação. Aliar os resultados séricos e urinários são a melhor forma de se diagnosticar a síndrome por sua complementariedade de informações.

A necessidade de trabalhos que comprovem resultados positivos em emprego clínico dos novos marcadores biológicos de IRA em cães e gatos fica evidente após esta revisão. Muito tem sido feito na área humana para se detectar marcadores precoces da IRA e esta área precisa ser melhor explorada na medicina veterinária.

\section{REFERÊNCIAS}

ABENSUR, $H$. Biomarcadores na nefrologia. Sociedade Brasileira de Nefrologia, [Internet].: Manual Roche Disponível em: www.sbn.org.br/pdf/biomarcadores.pdf. Acesso em: 30 ago 2015.

ALGE, L.J.; ARTHUR J.M. Biomarkers of AKI: A Review of Mechanistic Relevance and Potential Therapeutic Implications. American Society of Nephrology [EUA] v. 10, n.1, P. 147-155 2015. Disponível em: <http:// dx.doi.org/10.2215/ CJN.12191213> doi: 10.2215/ CJN.12191213

ANGELETTI S.; FOGOLARI M.; MOROLLA D.; CAPONE F.; CONSTANTINO S.; SPOTO S.; CESARIS M.; LO PRESTI A.; CICCOZZI M.; DICUONZO G. Role of Neutrophil Gelatinase-Associated Lipocalin in the Diagnosis and Early Treatment of Acute Kidney Injury in a Case Series of Patients with Acute Decompensated Heart Failure: A Case Series. Cardiology Research and Practice [Egito], v.2016, p. 1-9, 2016. Disponível em: <http:// dx.doi.org/10.1155/2016/3708210> doi:10.1155/2016/3708210

BELCHER, J. M.; EDELSTEIN, C. L.; PARIKH, C. R. Clinical Applications of Biomarkers for Acute Kidney Injury. American Journal of Kidney Disease; [S.I.] v. 57, n. 6, p. 930-940, 2011. Disponível em: <http:// dx.doi.org/10.1053/j.ajkd.2010.11.032.> doi:10.1053/j.ajkd.2010.11.032.

BELLOMO, R.; KELLUM, J. A.; RONCO, C. Acute Kidney Injury. Lancet, [Canada] v. 330, n. 9843, p. 756-766, 2012. Disponível em: <http://dx.doi.org/10.1016/S01406736(11)61454-2>. Acesso em: 19 ago. 2015.

BIRCHARD, S. J.; SHERDING, R. G.;. Clínica De Pequenos Animais, 3a ed. São Paulo: Roca, p.1001-1008. 2008.

BRAUN, J. P.; LEFEBVRE, H. P.; WATSON, A. D. J. Creatinine in the dog: a review. Veterinary Clinical Pathology. [Santa Barbara] v. 32, n. 4, p. 162-179, 2003. Disponível em: <http:// dx.doi.org/10.1111/j.1939-165X.2003.tb00332.x> doi:10.1111/j.1939-165X.2003.tb00332.x

BROWN, S. Introduction from the international renal interest society. Journal of Veterinary Internal Medicine. [Lawrence] v. 27 p. 1939-1676, 2013. Disponível em: <http://dx.doi.org/10.1111/jvim.12229>. doi: 10.1111/jvim.12229. 
CHIEN K. R.; ABRAMS, J.; PFAU, R. G.; FARBER, J. L. Prevention by chlorpromazine of ischemic liver cell death. The American Journal of Pathology. [Philadelphia] v. 88, n. 3, p. 539-553, 1997.

COBRIN, A. R.; BLOIS, S. L.; KRUTH, S. A.; ABRAMS-OGG, A. C.; DEWEY, C. Biomarkers in the assessment of acute and chronic kidney diseases in the dog and cat. The Journal of Small Animal Practice. [England] v. 54 p. 647-655, 2013. Disponível em: <http://dx.doi.org/10.1111/jsap.12150. doi:10.1111/jsap.12150.

COCA, S. G.; YALAVARTHY, R.; CONCATO, J.; PARIKH, C. R. Biomarkers for the diagnosis and risk stratification of acute kidney injury: A systematic review. Kidiney International [S.I.] v.73, n.9, p. 1008-1016, 2008.

DE LOOR, J.; DAMINET, S.; SMETS, P.; MADDENS, B.; MEYER, E. Urinary Biomarkers for Acute Kidney Injury in Dogs. Journal of Veterinary Internal Medicine. [Lawrence] v. 27, p.998-1010, 2013. Disponível em: <http://dx.doi.org/10.1111/jvim.12155>. doi: 10.1111/jvim.12155.

DEVARAJAN, P. Update on mechanisms of ischemic acute renal failure. Journal of American Society of Nephrology [USA] v. 17, p. 1503-1520, 2006.

DIBARTOLA, S. P. Clinical approach and laboratory evaluation of renal disease. In: ETTINGER, S. J.; FELDMAN, E. C. Textbook of veterinary internal medicine. $4^{\text {th }}$ ed. Philadelphia: Saunders, p.600-1614.2011.

ELMAS A.T.; KARADAG A.; TABEL Y.; OZDEMIR R.; OTLU G. Analysis of urine biomarkers for early determination of acute kidney injury in non-septic and nonasphyxiated critically ill pretern neonates. The journal of maternal-fetal and neonatal medicine [Abingdon]. 2016 v. 29, p 1-29. Disponível em: <http://dx.doi.org/10.1155/2016/3708210>. doi:10.1155/2016/3708210.

FORTERRE, S.; RAILA, J.; SCHWEIGERT, F. J. Protein profiling of urine from dogs with renal disease using proteinchip analysis. Journal of Veterinary Diagnostic Investigation. Columbia. v. 16, p.217-277, 2004.

GREENE, S. A.; GRAUER, G. F. Renal Disease. In: TRANQUILLI, W. J.; THURMON, J. C.; GRIMM, K. A. Lumb \& Jones' veterinary anesthesia and analgesia. $4^{\text {th }}$ ed. lowa: Blackwell publishing, p 915-919.2013.

HARA, T.; FUKUSAKI, M.; NAKAMURA, T.; SUMIKAWA, K. Renal function in patients during and after hypotensive anesthesia with sevoflurane. Journal of Clinical Anesthesia. Stoneham. v.10, p. 539-545, 1998.

HAYES, M. A.; GOLDENBERG, I. S. Renal effects of anesthesia and operation mediated by endocrines. Anesthesiology, Philadelphia. v. 24, p. 487-499, 1963.

HSU, W. L.; LIN, Y. S.; HU, Y. Y.; WONG, M. L.; LIN, F. Y.; LEE, Y. J. Neutrophil gelatinase-associated lipocalin in dogs with naturally occurring renal diseases. 
Journal of Veterinary Internal Medicine [Lawrence] v.28, n.2, p.437-442, 2014. Disponível em: <http://dx.doi.org/10.1111/jvim.12288> doi: 10.1111/jvim.12288.

JAIN V.; METHA Y.; GUPTA A.; SHARMA R.; RAIZADA A.; TREHAN N. The role of neutrophil gelatinase-associated lipocalin in predicting acute kidney injury in patients undergoing off-pump coronary artery bypass graft: A pilot study. Ann Cardiology Anaesthesia [EUA] v. 19, n.2., p. 225-230, 2016. Disponível em: <http:// dx.doi.org/10.4103/0971-9784.179590> doi: 10.4103/0971-9784.179590.

KAI, K.; YAMAGUCHI, T.; YOSHIMATSU, Y.; KINOSHITA, J.; TERANISHI, M.; TAKASAKI, W. Neutrophil gelatinase-associated lipocalin, a sensitive urinary biomarker of acute kidney inury in dogs receiving gentamicin. The Journal of Toxicological Sciences. Japan, v.38 n.2, p. 269-277, 2013.

KASHANI, K.; AL-KHAFAJI, A.; ARDILES, T.; ARTIGAS, A; BAGSHAW, S.M.; BELL, M.; BIHORAC, A.; BIRKHAHN, R.; CELY, C. M.; CHAWLA, L.S.; DAVISON, D.L.; FELDKAMP, T.; FORNI, L. G.; GONG, M.N.; GUNNERSON, K.J.; HAASE, M.; HACKETT, J.; HONORE, P. M.; HOSTE, E.A.; JOANNES-BOYAU, O.; JOANNIDIS, M.; KIM, P.; KOYNER, J.L.; LASKOWITZ, D.T.; LISSAUER, M. E.; MARX, G.; MCCULLOUGH, P.A.; MULLANEY, S.; OSTERMANN, M.; RIMMELÉ, T.; SHAPIRO, N.I.; SHAW, A.D.; SHI, J.; SPRAGUE, A. M.; VINCENT, J. L.; VINSONNEAU, C.; WAGNER, L.; WALKER, M. G.; WILKERSON, R. G.; ZACHAROWSKI, K.; KELLUM, J. A. Discovery and validation of cell cycle arrest biomarkers in human acute kidney injury. Critical Care. [London], v. 17, p. 1-12, 2013. Disponível em: <http:// dx.doi.org/10.1186/cc12503> doi: 10.1186/cc12503.

KATZ, R. Biomarkers and Surrogate markers: an FDA perspective. Neurotherapeutics. [USA] v 1, p.189-195, 2004. Disponível em: <http:// dx.doi.org/10.1602/neurorx.1.2.189> doi:10.1602/neurorx.1.2.189

KĘPKA, A.; WASZKIEWICZ, N.; CHOJNOWSKA, S.; ZALEWSKA-SZAJDA, B.; ŁADNY, J. R.; WASILEWSKA, A.; ZWIERZ, K.; SZAJDA, S. D. Utility of urinary Biomarkers in Kidney Transplant Function Assessemnet. In RATH, T. Current issues and future direction in Kidney Transplantation. [S.I.]:InTeach; 2013, p.490. ISBN: 978-953-51-0985-3, Disponivel em: <http://dx.doi.org/10.5772/54746>. doi: $10.5772 / 54746$.

KELLUM J.A; UNRUH M.L.; MURUGAN R. Acute kidney injury. Clinical Evidence [Londres], 2011. [online]. Disponível em: http://europepmc.org/articles/PMC3217737 acesso 20 jan 2015.

KOVALINKA, A. Myo-Inositol Oxygenase: A Novel Kidney-Specific Biomarker of Acute Kidney Injury?. Clinical Chemistry [Baltimore]; v. 60, $5^{\text {th }}$ ed., p. 708-710. 2014 Disponivel em: http:// doi: 10.1373/clinchem.2014.221960.

LIMA R. M. NAVARRO, L. H.; NAKAMURA, G.; SOLANKI, D. R.; CASTIGLIA, Y. M.; VIANNA, P. T.; GANEM, E. M. Serum cystatin is a sensitive early marker for changes in the glomerular filtration rate in patients undergoing laparoscopic surgery. Clinics. 
São Paulo, v. 69 n. 6, 9. 378-383, 2014 Disponivel em: http://dx.doi.org/10.6061/clinics/2014(06)02. doi:10.6061/clinics/2014(06)02.

LUBRANO, R.; MARANDOLA, M.; ANTONUCCI, A.; TELLAN, G.; ELLI, M.; SANTULLI, M.; LAURIA, D.; GIULIANA, G.; DELOGU, G. Hypotensive anesthesia with propofol and remifentanil: protective effect of alpha-tocopherol on renal function. Journal of Clinical Anesthesia. [Stoneham] v. 20, p. 164-169, 2008. Disponivel em: http://dx.doi.org/10.1016/j.jclinane.2007.09.015> doi: 10.1016/j.jclinane.2007.09.015.

MEAK, D. Distúrbios do sistema urogenital. In: BIRCHARD, S. J.; SHERDING, R. G. Manual Saunders: Clínica de Pequenos Animais. São Paulo: Roca; 2003, p.10011029.

MEDIĆ, B.; ROVČANIN, B.; VUJOVIĆ, K. S.; OBRADOVIĆ, D.; DURIĆ, D.; PROSTRAN, M. Evaluation of novel biomarkers of acute kidney injury: the possibilities and limitations. Current Medical Chemistry [Beijing]. 2016 Disponível em: http://www.ncbi.nlm.nih.gov/pubmed/26860999

MONAGHAN, K.; NOLAN, B.; LABATO, M. Feline Acute Injury: 1 Pathophysiology, etiology and etilogy-specific management considerations. Journal of Feline Medicine and Surgery. [S.I.] v. 14, n.11 p. 775-784, 2012. Disponível em: http://dx.doi.org/ 10.1177/1098612X12464458 doi: 10.1177/1098612X12464458

NEGISHI K.; NOIRI, E.; DOI, K.; MAEDA-MAMIYA, R.; SUGAYA, T.; PORTILLA, D.; FUJITA, T. Monitoring of urinary L-type fatty acid-binding protein predicts histological severity of acute kidney injury. The American Journal of Pathology. [Philadelphia]; v. 174(4), p.1154-1159, 2009. Disponível em: <http://dx.doi.org/10.2353/ajpath.2009.080644> doi: 10.2353/ajpath.2009.080644.

NEJAT, M.; PICKERING, J. W.; DEVARAJAN, P.; BONVENTRE, J. V.; EDELSTEIN, C. L.; WALKER, R. J.; ENDRE, Z. H. Some biomarkers of acute kidney injury are increased in pre-renal acute injury. Kidney International. Malden v. 81, p. 12541266, 2012. Disponível em: <http://dx.doi.org/101038/ki.2012.23. doi.101038/ki.2012.23

PALVIAINEN, M.; RAEKALLIO, M.; RAIAMAKI, M. M.; LINDEN, J.; VAINIO, O. Kidney-derived proteins in urine as biomarkers of induced acute kidney injury in sheep. The Veterinary Journal. [London], v. 193, p. 297-289, 2012.

PARIKH, C. R.; ABRAHAM, E.; ANCUKIEWICZ, M.; EDELSTEIN, C. L. Urine IL-18 is an early diagnostic marker for acute kidney injury and predicts mortality in the intensive care unit. Journal of the American Society Nephrology, [USA] v. 16 p. 3046-3052, 2005.

PRESSLER, B. M. Clinical Approach to advanced renal function testing in dogs and cats. The Veterinary Clinics of North America. Small Animal practice. [Philadelphia] v. 43, p. 1193-1208, 2013. Disponível em: <http://dx.doi.org/10,1016/j.cvsm.2013.07.011 >. doi: 10,1016/j.cvsm.2013.07.011 
PRICE, C. P.; NEWALL, R. G.; BOYD, J. C. Use of protein: creatinine ratio measurements on random urine samples for prediction of significant proteinuria: $\mathrm{A}$ systematic. Clinical Chemestry. [Baltimore], v. 51, p. 1-11, 2005.

PRICE, R. G. Early markers of nephrotoxicity. Comparative Clinical Pathology. [London], v. 11, p. 2-7, 2002.

REGO, A. B. A. S., KOGIKA M. M., SANTORO, M. L., HAGIWARA, M. K., MIRANDOLA, R. M. Eletroforese das proteínas urinárias de cães normais e cães com doença renal em gel de sódio-dodecil-sulfato poliacrilamida (SDSPAGE). Veterinária Notícias.[Uberlândia], v. 7, p. 65-72, 2011.

REINE, N. J.; LANGSTON, C. E. Urinalysis interpretation: how to squeeze out the maximum information from a small sample. Clinical Techniques in Small Animal Practice, [Philadelphia], v 20, p 2-10, 2010.

REMUZZI, G.; RUGGENENTI, P.; BENIGNI, A. Understanding the nature of renal disease progression. Kidney International, [Malden]. v. 51, p. 2-15, 1997.

REN H.; ZHOU X.; DAI D.; LIU X.; WANG L.; ZHOU Y.; LUO X.; CAI Q.; Assessment of urinary kidney injury molecule- 1 and interleukin-18 in the early post-burn period to predict acute kidney injury for various degrees of burn injury. BioMed Central Nephrology [Londres], v.16, n.142. 2015 Disponível em: <http://dx.doi.org/10.1186/s12882-015-0140-3>_doi: 10.1186/s12882-015-0140-3

RIVERS, B. J.; WALTER, P. A.; O'BRIEN, T. D.; KING, V. L.; POLZIN, D. J. Evaluation of urine gamma-glutamyl transpeptidade-to-creatinine ratio as a diagnostic tool in an experimental model of aminoglycoside-induced acute renal failure in the dog. Journal of the America Animal Hospital Association. [Lakewood]. v. 32, p. 323-336, 1996.

ROSS, L. Acute Kidney Injury in Dogs and Cats. Veterinary Clinical Small Animal. [S.I.] v. 41, p. 1-1, 2011. Disponível em: <http://dx.doi.org/10.1016/j.cvsm.2010.09.003>. doi: 10.1016/j.cvsm.2010.09.003

RUFATTO, F. H. F.; REZENDE-LAGO, N. C. M.; MARCHI, P. G. F.. Insuficiência Renal em Cães e Gatos. Revista Eletronica Univar [S. I.], [Curitiba], 2011; v. p.17173 ISSN 1984-431X.

SASAKI, A.; SASAKI, Y.; IWAMA, R.; SHIMAMURA, S.; YABE, K.; TAKASUNA, K.; ICHIJO, T.; FURUHAMA, K.; SATOH, H. Comparision of renal biomarkers with glomerular filtration rate in susceptibility to the detection of gentamicin-induced acute kidney injury in dogs. Journal of Comparative Pathology. [Edinburgh.] v. 51, p.264270, 2014. Disponível em: http://dx.doi.org/10.1016/j.jcpa.2014.06.001 doi: 10.1016/j.jcpa.2014.06.001.

SEGEV, G.; NIVY, R.; KASS, P. H.; COWGILL, L. D.A retrospective study of acute kidney injury in cats and development of a novel clinical scoring system for predicting outcome for cats managed by hemodialysis. Journal of Veterinary Internal 
Medicine [Lawrence]. 2013; v. 27 p. 830-839. Disponível em: http://dx.doi.org/10.111/jvim.12108> doi.10.111/jvim.12108.

SIEW E.D.; WARE L.B.; IKIZLER T.A.; Biological markers of acute kidney injury. Journal of American Society of Nephrology [EUA], , v.22, p. 810-820, 2011. Disponível em: http://dx.doi.org/10.1681/ASN.2010080796>. doi: 10.1681/ASN.2010080796.

SIROTA J.C.; KLEWITTER J.; EDELSTEIN C. Biomarkers of acute kidney injury. Journal of Toxicology. vol. 2011, Article ID 328120, 10 p, 2011. Disponível em: http:// http://dx.doi.org/10.1155/2011/328120 >: doi: 10.1155/2011/328120

SLADEN, R. N. Perioperative renal protection. ASA Annual Meeting Refresher Course Lectures, v. 242, p. 1-7.1993.

SODRÉ, F. L.; COSTA, J. C. B.; LIMA, J. C. Avaliação da função e da lesão renal: um desafio laboratorial. Jornal Brasileiro de Patologia e Medicina Laboratorial. [Rio de Janeiro], v. 43, n. 5, p. 329-337, 2007. Disponível em: http://dx.doi.org/10.1590/s1676-24442007000500005. doi 10.1590/s167624442007000500005

SOUZA, S. N. Aplicação dos exames complementares no diagnóstico da insuficiência renal crônica em cães. [Dissertação] Goiânia: Universidade Federal de Goiás, Escola de Veterinária e Zootecnia; 2011.

STEINBACH, S.; WEIS, J.; SCHWEIGHAUSER, A.; FRANCEY, T.; NEIGER, R. Plasma and Urine Neutrophil Gelatinase-Associated Lipocain (NGAL) in dogs with acute kidney injury or chronic disease. Journal Veterinary Internal Medicine.[Lawrence] v. 28, p. 264-269, 2014.

SUTTON, T. A.; FISHER, C. J.; MOLITORIS, B. A. Microvascular endothelial cell injury and dysfunction during ischemic acute renal failure. Kidney International [Malden] v. 62, p. 1539-1549, 2002.

THOEN, M. E.; KERL, M. Characterization of acute kidney injury in hospitalized dogs and evaluation of a veterinary acute kidney injury staging system. Journal Veterinary Emergency and Critical Care. v. 21, n. 6, p. 648-657, 2011 Disponível em: $\quad$ http://dx.doi.org/10.1111/j.1476=4431.2011.00689.x.> doi.10.1111/j.1476=4431.2011.00689.x

VADEN, S. L.; LEVINE, J.; BREITSCHWERDT, E. B. A retrospective case-control of acute renal failure in 99 dogs. Journal of Veterinary Internal Medicine. [Lawrence] v.11, n. 2, p. 58-64, 1997.

VIJAYAN A.;FAUBEL S.; ASKENAZI D.J., CERDA J.; FISSELL W.H.; HEUNG M.; HUMPHREYS B.D.; KOYNER, J. L.; LIU, K. D.; MOUR, G.; NOLIN, T. D.; BIHORAC, A. Clinical Use of the Urine Biomarker [TIMP-2] × [IGFBP7] for Acute Kidney Injury Risk Assessment. American Journal of Kidney Diseases [EUA], v.0, p. 272-286, 
2016 Disponível em: http://dx.doi.org/10.1053/j.ajkd.2015.12.033 doi: 10.1053/j.ajkd.2015.12.033

WARE, W. A. Glomerulonefropatias. In: NELSON, R. W.; COUTO, C. G. Medicina interna de pequenos animais. 5a ed. [Rio de Janeiro]: Elsevier; 2015. p. 575-582.

WINGFIELD, W. E. Segredos em medicina veterinária de emergência, $2 a$ ed., Porto Alegre: Artmed, p.488-497. 2004.

WORWAG, S.; LANGSTON, C. E. Acute intrinsic renal failure in cats: 32 cases (1997- 2004). Journal of American Veterinary Medicine Association, [USA] v.232, n.5, p. 728-732, $2008 . \quad$ Disponível em: http://dx.doi.org/10.2460/javma.232.5.728. doi: 10.2460/javma.232.5.728.

XAVIER, A.; PUZZI, M. B.; POLIZER, K.; LITFALLA, F.; PENA, S. B. Insuficiência Renal Aguda. Revista Científica Eletrônica de Medicina Veterinária, [Garça], n. 10, 2008; Disponível em: http://faef.revista.inf.br/imagens_arquivos/arquivos_destaque/BVOdrF56Aafrd9G_20 13-5-29-10-12-24.pdf ISSN: 1679-7353. Acesso em: 15 ago 2015.

XUE, W.; XIE, Y.; WANG, Q.; XU, W.; MOU, S.; NI, Z. Diagnostic performance of urinary kidney injury molecule-1 and neutrophil gelatinase associated lipocain for acute kidney injury in an obstructive nephropathy patient. Nephrology. [S.I.], v 19, p. 186-194, 2014. Disponível em: http://dx.doi.org/10.1111/nep.12173 doi: $10.1111 /$ nep. 12173

ZHOU, X.; MA, B.; LIN, Z.; QU, Z.; HUO, Y.; WANG, J.; LI, B. Evaluation of the usefulness of novel biomarkers for drug-induced acute kidney injury in beagle dogs. Toxicology and Applied Pharmacology. [San Diego] v. 280, p. 30-35, 2014. Disponivel em: http://dx.doi.org/10.1016/j.taap.2014.07.002. doi: 10.1016/j.taap.2014.07.002 